\title{
3 Research Square

\section{COVID-19 pandemic, challenges, and opportunities in Northern Uganda; Community overview and perspectives: A qualitative study using informant interviews.}

Eric Nzirakaindi lkoona

ICAP at Columbia University, Sierra Leone

Christopher Okot

Gulu Regional Referral Hospital

\section{Steven Baguma}

Gulu Regional Referral Hospital

Nelson Onira Alema

Gulu University, Faculty of Medicine, Department of Anatomy

Freddy WD Oyat

Uganda Medical Association, UMA-Acholi branch

Paska Apiyo

Gulu Regional Referral Hospital

Paska Layet

St. Mary's Hospital, Lacor

Francis Pebalo Pebolo

Gulu University, Faculty of Medicine, Department of Reproductive Health

Denis Acullu

Aga Khan Hospital, Mombasa, Kenya

Johnson Oloya Nyeko

Uganda Medical Association, UMA-Acholi branch, Gulu

Judith Aloyo

Rhites-N, Acholi, Gulu, Uganda

David Lagoro Kitara ( $\square$ klagoro2@gmail.com )

Gulu University, Faculty of Medicine, Department of Surgery https://orcid.org/0000-0001-7282-5026

\section{Research Article}

Keywords: COVID-19, challenges, interviews, opportunities, Northern Uganda

Posted Date: January 6th, 2022 
DOI: https://doi.org/10.21203/rs.3.rs-1233042/v1

License: (c) (1) This work is licensed under a Creative Commons Attribution 4.0 International License. Read Full License 


\section{Abstract \\ Background}

Severe Acute Respiratory Syndrome-Coronavirus 2 (SARS-CoV-2), a virus that causes COVID-19, has overwhelmingly interrupted human activities worldwide, especially in the low-to-middle income countries. Not much is reported about exclusive challenges and opportunities presented by the COVID-19 pandemic in some remote communities in Africa.

\section{Objective}

The objective of this study was to assess the community's views and perspectives on the challenges and opportunities of the COVID-19 pandemic in Northern Uganda.

\section{Methods}

We interviewed 36 participants (age range, 28-63 years), including health workers, civil servants, members of civil society, security forces, politicians, and staff of local government administration who were members of COVID-19 district task forces in Northern Uganda using qualitative study methods between August and September 2021. The initial selection of participants was purposeful, but the snowballing technique was later used to select others. The interview questions were pre-tested among health workers and laypersons who were not part of the main study. Participants described how the COVID-19 pandemic presented challenges and opportunities, and the experience could be used to strengthen community resolves to control the pandemic and any other in the future. A local IRB approved this study. Data were analyzed using thematic analysis.

\section{Results}

The current study findings revealed challenges but many opportunities during the COVID-19 pandemic in this community, including loss of lives and livelihoods, increased poverty, lack of personal protection equipment, uncertainties, stress, and anxiety among health workers in the community. However, it also offered opportunities for quality family time, increased engagement, sensitization, and mobilization of communities for health, improved general security of persons and property, increased budgets and logistics for government departments, reduced incidences of diarrheal diseases and road traffic accidents, increased incomes for task force members, and more interactions among members during task force meetings.

\section{Conclusion}


Although the COVID-19 pandemic presented enormous challenges to low-to-middle-income countries, there are opportunities in some communities that are worth mentioning. Information obtained in this study has practical lessons that disease control experts could use to develop strategies to organize communities better and conduct disease surveillance activities for the COVID-19 pandemic and others.

\section{Introduction}

Coronavirus disease 2019 (COVID-19) is a severe respiratory disease that results from infection with a new coronavirus (SARS-COV-2) [1]. One of the most critical issues related to the COVID-19 is the high rate of spread, which has resulted in millions of people being infected worldwide, and hundreds of thousands of deaths to date [1]. COVID-19 patients present with different symptoms: fever, dry cough, sore throat, loss of smell and taste, flu-like symptoms, headache, difficulty in breathing, chest pain, general body weakness, and fatigue, which are mild in about 80 percent of cases. Still, in severe cases, patients may develop respiratory distress or respiratory failure, and hence the need for intensive care units (ICUs) has increased globally [1].

Although the COVID-19 first spread slowly in Africa, confirmed cases of the virus on the continent have continuously been rising steadily since March 2020 [2]. The rapid spread of SARS-CoV-2 could be attributed to its numerous characteristics, including its high transmissibility, asymptomatic persons' ability to shed the virus, enormous numbers of asymptomatic persons, or mild symptoms but with the ability to transmit the virus, new variants, and super-spreading events $[3,4]$. Poor public health practices, disbeliefs, and misconceptions about the virus and its origin in many African communities are the other reasons for its rapid spread in the continent.

Currently, there are no effective drugs approved for the treatment of COVID-19 [4,5]. As a result, health care interventions are limited to preventive measures, supportive therapy, and vaccination. Several medications for the COVID-19 are being evaluated in Randomized Controlled Trials (RCT) [6], and preventative measures include social distancing, practicing hand hygiene and respiratory etiquette, wearing facemasks in public, self-isolation of people suspected of infection, and COVID-19 vaccination [7].

At least seven different COVID-19 vaccine candidates have demonstrated excellent efficacy in Randomized Controlled Trials, have been granted emergency use authorization by the World Health Organization (WHO), and are being rolled out globally [8-14]. Over 13 million doses have been administered in the African continent $[15,16]$.

Despite this progress, concerns about access to COVID-19 vaccines in Africa due to higher-income countries pre-emptively buying up vaccine supplies and hoarding have been described by some scholars and academicians as vaccine apartheid. The other reasons for limited COVID-19 vaccine access in Africa include the continent's low vaccine-manufacturing capacity and barriers to widespread delivery and uptake of COVID-19 vaccines across the African continent $[17,18]$. Given this prospect, African countries 
will likely continue to rely on implementing the existing public health prevention measures to contain the spread of SARS-CoV-2 for the foreseeable future.

It should be recalled that Uganda went through a lockdown beginning in March 2020, where it applied stringent measures (total lockdown). Initially, in early 2020, Uganda had registered one of the best statistics on the incidence, prevalence, number of hospitalizations, and COVID-19 related deaths in the East African region [19]. However, the country went through presidential, parliamentary, and local government elections from September 2020 to March 2021, characterized by massive rallies and electioneering processes.

By December 2020, Uganda had experienced the first wave of COVID-19, which affected a few people, 40,000 confirmed cases, and 300 deaths compared to other countries in the region [20]. Uganda experienced a severe second wave of COVID-19 in May, June, and July 2021 [21]. The country registered three times the number of COVID-19 cases from the first wave and more than 2000 deaths, overturning the country's successes in controlling the pandemic [21]. COVID-19 related loss of lives, livelihoods, increased poverty, economic losses, and psychosocial problems have become significant challenges facing communities in Uganda [21].

However, COVID-19 related opportunities in many communities in Uganda have remained unreported. The opportunities created by the COVID-19 pandemic have enabled the Government of Uganda to strengthen disease surveillance systems, increase the number of beds in health centers and hospitals, increase the numbers of Intensive Care Units (ICUs), establish oxygen plants in most Regional Referral Hospitals, procured ambulances, and many supplies that helped save the lives of many people and communities in Uganda.

The Ugandan Government must be applauded for taking advantage of the COVID-19 pandemic for strengthening its healthcare systems amidst many social and economic uncertainties. Because of these experiences, authors developed interests to assess the views and perspectives of communities in Northern Uganda on their experiences during the COVID-19 pandemic.

The purpose of this study was to gather information from the community of Northern Uganda so that disease control experts could use it to organize and strategize on surveillance, prevention, and control during and after the COVID-19 pandemic.

The objective of this study was to assess the views and perspectives of communities in Northern Uganda on the challenges and opportunities resulting from the COVID-19 pandemic from March 2020 to September 2021.

\section{Materials And Methods}

\section{Study design}


We employed qualitative study methods using informant interviews to assess experiences and lessons learned during the COVID-19 pandemic among health workers, security forces, civil society, politicians, district task forces, and communities. A core strength of this design was to allow participants to freely describe, with minimal limitations, their lived experiences during the COVID-19 pandemic and lockdowns. Participants were encouraged to express their opinions on what they considered were strategies, challenges, and opportunities achieved during the COVID-19 pandemic. Therefore, a qualitative study design was deemed suitable for answering these research questions. Informant interviews were conducted between August and September 2021.

\section{Study Settings}

This study was conducted in Gulu City, Nwoya, Pader, and Gulu districts in Northern Uganda. The four districts where the study was conducted are part of the districts that form the Acholi subregion in central northern Uganda. The area has just emerged out of a 20-year-old war between the Government of Uganda and the rebel Lord's Resistance Army (LRA). The population is in the recovery period of the civil war. There are ten districts in the Acholi subregion with a total estimated population of one million, eight hundred thousand people.

During this study, Uganda had just eased the second lockdown. The number of COVID-19 patients had significantly reduced in COVID-19 Treatment Centers (CTUs) in many health facilities in Northern Uganda. Health workers remained the frontline workforce (especially nurses, doctors, and laboratory staff). Many health workers canceled their annual leaves and were recalled from leave to care for patients and provide the required clinical services. In addition, the task forces were set up by the Government of Uganda along the layers of administrative structures (national and districts) of the country to support the management, prevention, and control of the COVID-19 pandemic in communities. Weekly task force meetings were conducted in the four districts where this study was conducted.

The President of Uganda had announced new methods of controlling the spread of the virus, where $30 \%$ of staff in public and private organizations were allowed in offices. These COVID-19 control measures were intended to disrupt day-to-day contacts between management, administration, and the community to break the cycle of person-to-person physical contacts and the transmission cycle of COVID-19.

Participants: Interviews were conducted with 36 participants -twenty-one health workers, five members of security forces, two members of civil society, four politicians, and four members of the local government administration who were members of the COVID-19 district task forces in Northern Uganda. We initially adopted a purposive sampling strategy [22], not aiming to achieve statistical representation of the study population. Subsequently, the snowballing method became evident as those interviewed suggested the next person to provide additional information on COVID-19 [23]. Reynosa et al. (2020:1) mentioned that face-to-face interaction is the hallmark in qualitative research data collection because it enables rapport building, open and honest dialogue with research participants, and showing empathy [23]. This study adopted the snowballing technique definition as a sampling method whereby the sample population was built up by recruiting potential participants from known informants [24]. 
To start the snowballing, we engaged two members of the district task force well-known in the community via community organizations and networks. Participants were selected to represent selfidentifying as members of the COVID-19 district task force set by the Government of Uganda, adults living in the district of study and having experience in the management of COVID-19, a year after its budding as a pandemic. The snowballing aspect involved researchers asking interviewees to identify and refer others they knew fit the selection criteria.

Ritchie et al. (2013) noted that snowballing sampling works well for recruiting dispersed and small populations with selection criteria that may not be as widely disclosed due to the topic's sensitivity [24]. However, by recruiting new participants from an existing sampling pool, the researchers risked the sample's diversity as sampling members would refer a potential participant from the same place of work or institution. However, this procedure allowed us to identify participants from various experiences related to our research questions.

As data collection and analysis progressed in parallel, the sample size was adapted to the variety, the extent of experiences, and opinions captured in line with the principle of the power of information until information saturation was reached.

The snowballing method enabled us to obtain all the required participants to gather the information we required eliminating the need to publicize the study among health workers, security forces, civil society, politicians, and district administrators who were members of the district task forces.

Appointments for interviews were made with participants before the actual interview sessions and, on most occasions, twenty-four hours in advance. Interview sessions lasted between 30-45 minutes, although the conversation lasted more than one hour on a few occasions.

Socio-demographic characteristics (age, sex, and occupation) and the district of work or residence of participants who had completed interviews were reviewed during the data collection process, enabling targeted inclusion of participants not well represented to optimize diversity in the sample, achieving a balanced gender representation and widespread coverage of the region (Additional file 1).

\section{Research questions}

This study was guided by seven research questions which were.

1. In your opinion, what were the reasons for the surge in coronavirus cases in this region?

2. In your opinion, what were the most typical complaints/presentations of COVID-19 patients in this hospital or district?

3. In your opinion, what were the challenges you faced with the COVID-19 patients, and what remedies do you recommend?

4. In your opinion, what were the opportunities presented by the coronavirus pandemic to your hospital or district? 
5. In your opinion, what were the main COVID-19 success stories from your hospital or district that you wish to share?

6. In your opinion, what were the main challenges your staff and hospital/district faced during this pandemic?

7. What advice would you give to the population in the region on how to protect against coronavirus infection? (Additional file 2).

\section{Interview process and quality assurance}

A team of twelve senior researchers experienced in qualitative study methodologies conducted the interviews. Before data collection, the questionnaire was pre-tested among health workers and laypersons; however, the pre-test results were excluded from the main study results. The pre-test informed the team to re-word some questions to improve clarity and ensure face and content validity.

At interviews, no question was mandatory, as was provided in the informed consent form. Participants were free to answer any question and opt-out if they felt they did not want to, without any adverse consequences. All questions provided to participants were reassuring and elicited responses that were included in the data collection form.

The Gulu Regional Referral Hospital Research and Ethics Committee approved this study. The purpose of the study was explained to participants, and only participants who gave written informed consent to the study were interviewed as guided by the Standards for Reporting Qualitative Research Recommendations [25]. Researchers contacted and invited participants for the interview at a time and place convenient to participants and within their work districts. Although health workers and local leaders were initially targeted for interviews, the snowballing method revealed vital stakeholders researchers included in the study. The stakeholders identified by the snowballing included members of the army, police, the prisons, private security organizations, civil society, NGOs, local councilors, and community members. The snowballing allowed us to include diverse persons who provided wide-ranging and rich perspectives on the research questions. However, only participants who could communicate in English were interviewed as not all the researchers could speak Acholi, the main dialect in the region.

Participants' socio-demographic characteristics such as age were obtained at the end of the interview to avoid creating uneasiness among participants at the beginning of the discussions. In the meantime, the research team met weekly on Zoom to discuss potential themes from participants' responses during data collection. Data collection for this study ended when information saturation on the subject matter had been achieved.

\section{Data analysis}

Data from the interviews were cleaned and thematically analyzed. The first author (a Ph.D. degree holder in Public Health) with extensive training and experience in qualitative research methods, thematically analyzed data in line with the suggestions from Braun and Clarke [26]. Before conducting data analysis, 
the analyst (the first author) underwent bracketing by reading literature and openly discussing various aspects of his knowledge that may influence data analysis with co-authors [27]. Identified prior knowledge on the subject and strategies to minimize its effects on data analysis were openly discussed among co-authors. The first author immersed himself with the data by reading and re-reading responses from participants four times [26]. The researcher wrote down all the identified themes and the corresponding quotations that endorsed each theme from the data. After this step, the research team was invited to read and re-read each theme and the related quote(s) to confirm appropriateness and accuracy. Any disagreements among researchers on the evolving themes were resolved through discussions and consensus. During these discussions, all researchers refined the themes of this study. In addition, researchers presented the leitmotifs to five study participants to determine if the developed themes represented their views. Furthermore, two external qualitative research experts were given and requested to review samples of the articles and their corresponding quotes to ensure external validity. Still, the study utilized the consolidated criteria for reporting qualitative health care research [28].

\section{Results}

A total of 36 (21 males, 15 females) study participants with age (range, 28-63 years) were interviewed in this study. Participants included: 21 health workers (clinical and administrative staff), five members of the security forces, two members of the civil society, four politicians, and four members of the local government administration who were members of the district task forces (Table 1). Participants' experiences on the COVID-19 response varied according to the service type, geographical location, and roles played. However, all participants overwhelmingly conveyed numerous COVID-19 pandemics and lockdown-related challenges and opportunities (Additional file 3). 
Table 1: Socio-demographic characteristics of participants

Variables $\quad$ Frequency $(n=36) \quad$ Percent (\%)

\section{Sex}

\begin{tabular}{lll} 
Male & 21 & 58.3 \\
\hline Female & 15 & 41.7
\end{tabular}

\section{Occupation}

\begin{tabular}{lll}
\hline Health workers & 21 & 58.3 \\
\hline Members of security forces & 5 & 13.9 \\
\hline Politicians & 4 & 11.1 \\
\hline Members of civil society & 2 & 5.6 \\
\hline Members of local government administration & 4 & 11.1 \\
\hline Ages (years) & & \\
\hline$\leq 40$ years & 13 & 36.1 \\
\hline$>40$ years & 23 & 63.9 \\
\hline Districts & & \\
\hline Gulu & 12 & 33.3 \\
\hline Pader & 5 & 13.9 \\
\hline Nwoya & 6 & 16.7 \\
\hline Gulu City & 13 & 36.1
\end{tabular}

In Table 1, most participants were males 21(58.3\%), health workers 21(58.3\%), more than 40 years of age 23(63.9\%), and from Gulu City 13(36.1\%).

The following sections of the results present participants' descriptions of opportunities and challenges faced by communities during the COVID-19 pandemic, the impact of the changes on staff, community, health systems, the dilemmas and challenges encountered, and the opportunities created in these low resource settings.

For the health workers, changes in services and the nature of work were enormous. The most immediate consequence of the pandemic as described by participants (health workers) was the rapid reorganization of the in-and outpatient departments and community services to minimize risks of infection with the COVID-19, where essential and non-essential services were defined. Some health workers' annual leaves were canceled, and those on leave were recalled, joining others to provide the COVID-19 treatment 
services and other prioritized essential services. These decisions were usually within the management team structure and were cascaded to service managers in different sections of health facilities.

Results of the interviews are presented according to participants' views and perspectives. In addition, the participant's code, age, sex, and roles played in the management of COVID-19 were included in each quotation.

\section{On question1: In your opinion, what were the reasons for the surge in cases of coronavirus in this region?}

Themes developed from interviews were: (i) Open defiance to COVID-19 Infection, Prevention, and Control (IPC), Standard Operating Procedures (SOPS) compliance, (ii) uncontrolled movement of persons and porous borders, (iii) A lack of IPC materials and poor living conditions

\section{Open defiance to the COVID19 IPC SOPs compliance}

Participants mentioned community members' non-compliance to COVID-19 infection, prevention, and control (IPC) standard operating procedures (SOPS) as the main reason they thought led to the surge in COVID-19 in Northern Uganda, which was experienced one month before this study. They mentioned that community members did not observe IPC SOPS for many reasons, including open defiance with compliance to IPC SOPS due to stubbornness and general knowledge gaps among community members on how the virus was transmitted and how to prevent its spread. Cultural beliefs that diseases such as COVID-19 existed spiritually made it challenging to prescribe IPC SOPS.

Also, there were beliefs among members that COVID-19 was non-existent but a creation by the government of Uganda to curtail opposition politicians from their campaign rallies.

"This increase in numbers of COVID-19 cases in the region came because of the relaxation of the public in following guidelines given by the government to protect and prevent the spread of the virus ... I have also seen mass community gatherings during this period," said GX\#5 (a 59-year-old, male, member of security forces).

"There is inadequate knowledge on prevention and control of COVID-19 in the community. The charcoal business has become a problem where person-to-person contacts have increased, food transportation and truck movements into and out of districts have not been restricted. There is negligence to adhere to SOPs, and there is no observation of presidential directives limiting the number of people in social gatherings to less than 20," said GX\#32 (a 47-year-old male health worker).

"There is inadequate population sensitization; most people believe coronavirus disease is only for the rich. There are many violations of SOPS; there is no wearing on facemasks by most people, no observation of social distancing, hand washing, and social gathering standard procedures. Also, there are selfish behaviors among community members where people intentionally transmit infections to others, claiming that they cannot die alone. In addition, people could not differentiate the COVID-19 symptoms from other diseases, so those who had symptoms continued to mix freely without limitations. Also, there 
are many stigmas related to COVID-19 cases; some did not want to test for fear of stigma related to the disease. Lastly, social media posts have portrayed a lot of negative information on COVID-19 vaccine, vaccination, and the disease," said GX\#21 (a 28-year-old male health worker).

"Poor cultural beliefs and practices in some communities, for example, gathering for burials, weddings, sports, markets, and lack of researched information. Coordination gaps between lower and higher stakeholders in many communities were responsible for the surge in COVID-19 cases in Northern Uganda," said GX\#14 (a 44-year-old male, DTF).

"...... those who got immunized with the COVID-19 vaccine gained false confidence and stopped wearing facemasks even when in public. Lastly, the community did not differentiate between the COVID-19 vaccination from other forms of vaccinations, and this led to the failure to complete the recommended dosages of the vaccine and the care during and after COVID-19 vaccination," said GX\#4 (a 40-year-old female member of security forces).

\section{Uncontrolled movement of persons and porous borders of Northern Uganda.}

The study participants also believed the uncontrolled inter-district and cross-border movement of persons too fueled the second wave of COVID-19 in Northern Uganda. The failure of authorities to control activities of international truck drivers within the country, lack of COVID-19 testing facilities at border points, overcrowding at border points, uncontrolled contacts between community members and international truck drivers who were not tested for COVID-19, and porous borders with South Sudan were factors of great concern mentioned by participants. The porous borders allowed uncontrolled movement of people between Northern Uganda and South Sudan, a country that has instituted limited COVID-19 control measures. The unplanned and uncoordinated movement of people before the second lockdown across different districts was mentioned by many study participants as a significant cause for the second wave in Northern Uganda.

"... porous borders with South Sudan and northern Uganda are traversed by the East African highway from Mombasa to South Sudan with many resting stopovers for international truck drivers in Gulu district facilitated regular contacts between the community with the truck drivers. This could have been one of the reasons for the surge in the COVID-19," was mentioned by GX\#33 (a 52-year-old male, DTF).

".....movement of people from Kampala to Acholi subregion before the second lockdown brought COVID19 infections from Kampala to Acholi subregion. The inadequate sensitization of the community on the disease was yet another problem. Most communications from the Ministry of Health were made over televisions and radios. Yet, most people do not have televisions and radios, and so many people miss information from the government. In addition, there was disbelief in what the government said about the COVID-19. They thought it was a political disease and people never observed SOPS during the campaigns," said GX\#35 (a 38-year-old male, Politician). 
"The uncoordinated and unplanned release of students from boarding schools caused the surge of COVID-19 as most students in boarding schools had already been infected with the coronavirus. The announcement of a second lockdown a week before its implementation allowed people to move upcountry where SOPS were not observed in buses and public transports. This movement made several families and students move upcountry; amongst them were people infected with COVID-19. Hence, they caused the huge infection and surged in this region," said GX\#36 (a 39-year-old male health worker).

"........ people in Northern Uganda should note that this is a pandemic and a global health issue. Northern Uganda is no exception. The East African highway traverses Northern Uganda from Mombasa to Sudan. There are many stopovers in the Gulu district that international truck drivers use. These stopovers are commercial centers in Gulu where truck drivers mingle freely with the local population. This could be one of the reasons for the surge in cases of COVID-19 in the region," said GX\#33 (a 52-year-old male, DTF).

".......the virus took the population by surprise; long-distance truck drivers were responsible for spreading the virus in communities in Northern Uganda. Congestions and failure to follow SOPS at border points were part of the reasons for the surge in cases in the region," said GX\#2 (a 55-year-old male, member of the security forces).

\section{The lack of Infection, prevention, and control materials and poor living conditions among community} members. Many participants mentioned the lack of IPC and poor living conditions among residents of Northern Uganda as part of the reasons that led to the surge in COVID-19 cases. Other issues mentioned were the high poverty-related matters in many communities, especially the inability to buy IPC materials such as facemasks, hand sanitizers, drugs for treatment. Overcrowding in poorly ventilated rooms, failure to avoid public places and high-risk places because of the nature of their jobs were issues of concern. On the other hand, health workers lacked the required IPC materials and PPEs, had work burnout, work fatigue, lacked facilities for COVID-19 isolation, and supplies and drugs to treat cases. In addition, many participants believed that most health workers got infected with the virus, and they could have been responsible for the surge in COVID-19 cases in Northern Uganda.

"... most community members did not believe that the COVID-19 virus existed in their community. They thought it was a rumor. People found it hard to wear face masks, and masks were uncomfortable. The high rate of poverty forced people not to follow the SOPS. The community could not afford basic requirements for infection, prevention, control, and management of COVID-19," said GX\#13 (a 31-year-old female, member of security forces).

".....Failure to isolate contacts of COVID-19 from the community. There was ineffective case management using the home-based care model because the community could not afford proper places for isolation. Suitable rooms for isolation and other requirements for treatment at home were lacking," said GX\#10 (a 54-year-old female Politician).

"Health workers, especially nurses who had worked so hard in the first wave, had become fatigued and relaxed from following infection prevention and control (IPC). The lack of PPEs, drugs and supplies 
greatly affected health workers. The community, too, did not prioritize looking for other incomes to feed themselves during the lockdown. So, they became involved in risky activities to find a living," said GX\#23 (a 44-year-old female health worker).

\section{On question 2, in your opinion, what were the most typical complaints/presentations of COVID-19 patients in your hospital or district?}

There have been no uniform clinical presentations of the COVID-19 cases in this community. Some were asymptomatic, while others presented with varied symptoms including headache, sore throat, general body pains, malaise, chest pain, running nose, difficulty in breathing, dry cough, itchy throats, high-grade fever, loss of appetite, loss of smell and tastes, and excessive sweating.

"In the first wave, most COVID-19 patients suffered from dry cough, running nose, sore throat, loss of smell and taste, headache, chest pain, malaise, back pain while in the second wave, fatigue/exhaustion/tiredness, headache, loss of smell and taste, cough and running nose, malaise, myalgia, and backaches were the commonest presentations," said GX\#28 (a 38-year-old, male, health worker).

"Fever (high-grade fever), dry cough, sore throats, running nose, and difficulty in breathing were the commonest clinical presentations of patients with COVID-19," said GX\#25 (a 63-year-old male health worker).

"Cough, headache, breathing problems, and fever were the commonest reported complaints," said GX\#14 (a 44-year-old male, DTF).

On question 3, in your opinion, what were the challenges you faced with the COVID-19 patients, and what remedies do you recommend?

Participants mentioned several issues which were classified as (i) COVID-19 Case management issues (there was no standard treatment protocol, there were multiple drug use, lack of fuel for referral of COVID19 patients, lack of personal protection equipment (PPEs), and inadequate space for isolation of patients in health facilities), (ii) Violent reactions on security forces (iii) Widespread community stigmatization on COVID-19 (iv) Inadequate health management systems in health facilities.

"There were varying and multiple drugs used for the treatment of COVID-19, and this was problematic. There was a lack of fuel which affected referrals of patients from one health facility to another. There was a widespread stigma on COVID-19 in communities, which affected commitments, especially among health workers. In addition, the low uptake of COVID-19 vaccines among health workers was demoralizing to communities. The proposed remedies are increased risk communication to communities. Implementing partners (IP) should support districts and continue with risk communication through their IP agents and the media," said GX\#1(a 43-year-old female health worker). 
"There were shortages of PPEs for the management of COVID-19 patients. Psychological distress, including fear and anxiety among health workers, was widespread. My proposed remedies are to provide adequate PPEs, increase incentives to staff and give psychological support to health workers," said GX\#6 (a 45-year-old male health worker).

"There is a lot of psychological and emotional stress among health workers and community members. There is a need for ongoing counseling of patients and psychosocial support to health workers and communities," said GX\#1(a 43-year-old female health worker).

The security forces faced challenges: These were mainly on where to detain COVID-19 suspects, how to avoid exposing detainees in detention centers, how to transport suspects who were COVID-19 positive, how to interrogate them, and present them to courts of law.

"We had problems with where to detain COVID-19 suspects in police cells and how to isolate them from other suspects considering that there were no isolation rooms designated for cases, how to interrogate them in police stations and how to transfer them to the courts of law for prosecution. Unfortunately, the courts were also closed during the lockdown period," said GX\#13 (a 31-year-old female security forces member).

Widespread community stigmatization and denials of COVID-19. Many participants mentioned widespread stigma on COVID-19 patients, contradictions, difficulty in accepting positive test results, fear of death, anxiety, panic, and loneliness among community members during the period.

"There is a high level of stigmatization among communities on COVID-19 cases, and knowing one's status has become a problem," said GX\#4 (a 40-year-old female security forces member).

".....challenges of the widespread social stigma of people diagnosed with COVID-19 who were isolated from other members of the community have reached a level of concern. Many medics had inadequate case management and follow-up information, creating many uncertainties and fear in communities. In addition, the home-based care management of COVID-19 has been challenging due to a lack of funds, drugs for treatment, PPEs, and human resources for care. Management of moderate-severe cases in the community has become problematic as there are no health workers assigned for that purpose," said GX\#32 (a 47-year-old male health worker).

"Heavy drinking, overcrowded markets with vendors who do not follow SOPS, failure to follow social distancing rules and wearing of facemasks in public, and an unregulated number of passengers in public vehicles were the main reasons for the surge in COVID-19 cases in Northern Uganda. Inadequate PPEs made health workers fear handling COVID-19 patients. In addition, there was a denial of positive test results, especially when the patients were stable, yet many people were at risk of contracting the virus. I propose that the government should provide PPEs and continue sensitizing the community as the immediate remedy to the problem," said GX\#8 (a 33-year-old female health worker). 
Challenges of inadequate information, limited aeration in dwelling/sleeping places with limited resources to afford the purchase of drugs and proper diet were major problems in the community. I propose improved research and dissemination of information on the virus; get patients in well ventilated facilities and houses; drugs for treatment should be centrally procured and given to patients," said GX\#14 (a 44-year-old male, DTF).

"...... generally, there is lack of money in the community, lack of drugs, widespread stigma on the disease in the community. Most community members lack food to enable them to stay at home, and patients take longer to recover during this second wave of COVID-19," said GX\#1(a 43-year-old female health worker).

"Keeping infected COVID-19 patients isolated in the home-based care management has become problematic and should be limited because it has become unbearable for the community due to lack of resources for home-based care," said GX\#2 (a 55-year-old male member of security forces).

A member proposed the following as remedies, "There is a need for psychosocial support and counseling to patients and their caregivers. More training of health workers, village health teams (VHTs), and community leaders on COVID-19 case management and referrals. There is a need to lobby for more support from partners and well-wishers, training and recruiting volunteers to provide additional labor support to the health workers are required. There is also a need to hire tents to serve as holding or treatment centers for moderate-to-severe cases awaiting referrals," said GX\#36 (a 39-year-old male health worker).

Inadequate health management systems in health facilities. Participants mentioned many challenges experienced in many health facilities during the COVID-19 pandemic and the effects of the lockdown measures implemented across the county. These included the lack of proper isolation units for COVID-19 cases, lack of oxygen, inadequate staff to manage cases, and lack of ambulance in some health facilities.

"There were several problems in the COVID-19 treatment centers, including an inadequate number of staff, inadequate space for isolation, and sometimes shortage of oxygen. Some health facilities lacked ambulance for referral of patients," said GX\#34 (a 28-year-old female, DTF).

\section{On Question 4, what opportunities did the coronavirus pandemic present to your hospital or district?}

Themes developed from interviews included: (i) Better support to health facilities (ii) increased support to health workers, and district leaders (iii) Improved security of persons and property (iv) Increased community engagement, sensitization, and mobilization on COVID-19 (v) Improved performance of the health sector

This question was the most extensively discussed questions among participants and cut across many issues categorized as (i) better support to health facilities. Participants reported increased funding from central and local governments, donors, and local communities to health facilities during the COVID-19 pandemic. The government established oxygen plants in all regional referral hospitals; put up 
handwashing facilities at most entry points to and from public buildings. It procured and provided beds and mattresses for patients in health facilities; procured and increased the numbers of ambulances in most health facilities; it increased sizes and spaces of CTUs for the management of COVID-19 patients; and more infrastructural improvement at the Regional Hospital, especially the construction and equipping of ICUs.

"Hospitals received donations of oxygen cylinders, oxygen concentrators, mattresses for patients and PPEs for staff, and all equipment and supplies were beneficial during the pandemic," said GX\#7 (a 37year-old male, Politician).

“....... Government has improved drug supplies and deliveries, and this was accompanied with an improved screening of patients at many points in government facilities, in addition to the increased allocation of fuel for ambulances and hospitals for running vehicles and standby generators," said GX\#16 (48-year-old, female, health worker).

"There is increased funding support from local and external donors to health facilities, and there are better IPC measures that can improve other service indicators such as WASH, personal hygiene, incidences of diarrheal diseases, and water-borne illnesses in communities. There are increased health workers' refresher training, improved coordination, and discussions on health issues," said GX\#1(a 43year-old female health worker).

Increased support to health workers and district leaders during the COVID-19 pandemic. Participants reported many supports accorded to health workers and district leaders during the pandemic and lockdown. These included increased allowances and training of health workers on care and management of COVID-19 and allowances for the district leaders (especially RDCs). In addition, there was an increased fuel allocation for operating emergency vehicles, expanded logistics, including more cars, especially ambulances, facemasks, sanitizers, and hand washing materials.

".............. there is a dedicated and well-facilitated team of health workers at the CTU that could not sleep during the second wave of COVID-19. In addition, intensive training of health workers by WHO and UNICEF has been beneficial. Health facility management support has become crucial and increased cooperation among staff at all levels," said GX\#14 (a 44-year-old male, DTF).

"Beneficiaries of funds from the government, for example, the Resident District Commissioners (RDCs), had increased allowances. More fuel, new vehicles, funds, hand sanitizers, soap, and water dispensers for the different government facilities have been procured and delivered. However, there was the unequal distribution of these materials," said GX\#5 (a 59-year-old male, member of security forces).

"Gulu was one of the districts severely affected by the COVID-19 pandemic, with the CTU managing more than 800 cases with a recovery rate of over 96\%. This is something to be proud of......" said GX\#27 (a 36year-old female health worker) 
"Ambulances were acquired for the district. Now we have four which has made referrals of patients a little easier. It has exposed weaknesses of our leaders in the district and how they are not considerate to communities," said GX\#24 (a 39-year-old male health worker).

Improved security of persons and property during the COVID-19 pandemic: Participants mentioned the general improvement in the safety of persons and property during the COVID-19 pandemic and the lockdown. Night curfews imposed by the Government helped reduce the workload of security forces and reduced incidences of crimes, especially burglary and petty thefts.

"There is a general security improvement because of adherence to night curfew regulations. Restrictions to public places, for example, markets, bars, and lodges helped reduce numbers of COVID-19 cases," said GX\#2 (a 55-year-old male, member of security forces).

"There is improved coordination of responses at district level and community's attitudes have changed to the positive. People got tired of seeing COVID-19 patients die in large numbers. This has led to a change in people's attitudes, and there is increased wearing of a facemask in public among community members," said GX\#4 (a 40-year-old female member of security forces).

"Many people who became sick with COVID-19 were treated and recovered. This pandemic brought in some level of discipline, including regular hand washing, regular use of hand sanitizers, and restricted movements at night. This has improved the general security and has eased the work of the police. Night curfews have done well in reducing crimes in the community," said GX\#13 (a 31-year-old female, member of security forces).

"............the success stories are that the home-based care management of COVID-19 has reduced the burden on health facilities. The pandemic has also improved productivity/revenue/employment, especially around factories that provide PPEs, facemasks, and hand sanitizers," said GX\#1(a 43-year-old female health worker).

Increased community engagement, sensitization, and mobilization on COVID-19. Many participants mentioned regular sensitization and mobilization of communities on the management, prevention, and control of COVID-19, improved hygiene and sanitation at the personal and community level, increased good willpower with communities donating funds and materials to support the most vulnerable members of their communities, and creation of internal funding mechanisms in communities. In addition, there were reduced incidences of water, sanitation, and hygiene (WASH) related diseases and road traffic accidents.

"Community engagement on the COVID-19 prevention and control resulted in a decrease in the rising cases in the high-risk area of Puranga Ongonyo. The political and technical team addressed the community, which resulted in a decrease in new cases. After that, there was massive uptake of testing by the community. Positive cases were followed up and managed through a home-based care model. There were no referred cases from the same community for hospital care and management during the period. In 
addition, the transmission rate of COVID-19 was reduced through the risk communication team that engaged the community. The district task force reactivated teams and formed task forces from village to district levels. Importantly, continuous surveillance ensured early detection and management of positive cases of COVID-19," said GX\#32 (a 47-year-old male health worker).

"Sensitization, engagement, and mobilization of the community increased during the pandemic. Communities were encouraged to erect handwashing facilities to improve hygiene, in addition to regularly using hand sanitizers," said GX\#35 (a 38-year-old male, Politician).

"Many residents donated to district task forces so that the donations could be used to break down the cycle of COVID-19 transmission. An 80-year-old woman demonstrated this by donating her UGX10,000 shillings to support DTF. In addition, people supported the COVID-19 treatment centers by donating food items, amongst other things. Residents were so committed to the task force's activities that many members of DTF would travel long distances to attend DTF meetings. This self-motivation and commitment among the DTF were awesome as it was not common. Furthermore, radios and other media houses were used for disseminating information to the local community, and this demonstrated collective efforts to fight and eradicate the virus," said GX\#33 (a 52-year-old male, DTF).

"......personal and household hygiene has improved; hand washing is now commonly practiced in homes and trading centers in the region," said GX\#34 (a 28-year-old female, DTF).

"There has been improvement in family hygiene, and this has caused a reduction in numbers of diseases caused by poor hygiene such as diarrhea," said GX\#36 (a 39-year-old male health worker).

"The COVID-19 pandemic led to better maintenance of roads for easy movement of ambulances. There were reduced cases of road traffic accidents due to restrictions of movements of vehicles and motorcycles," said GX\#33 (a 52-year-old male, DTF).

Improved performance of the health sector. Many participants mentioned improved disease surveillance and management performance during the COVID-19 pandemic in many districts. In addition, the pandemic created an opportunity for health system reforms especially using a multisectoral and multistakeholder approach to disease management from the local level to the center by creating multistakeholder committee from the village, parish, sub-county district task force, districts, and national level, which helped improve disease surveillance among community members.

"There is a significant improvement in the epidemiological surveillance of diseases but particularly on COVID-19," said GX\#21 (a 28-year-old male health worker).

"The use of local medicines and herbal medicines have promoted quicker recovery from COVID-19. Adherence to SOPS keeps one safe from contracting the virus," said GX\#12 (a 49-year-old male health worker). 
"Many more of our teaching staff became sick but luckily recovered from the illness following our treatment. In addition, many staff was trained on the COVID-19 pandemic and the management of cases. It is important to know that almost all my staff have received COVID-19 vaccines, and a certificate of vaccination completion has been issued to them, including students," said GX\#25 (a 63-year-old male health worker).

"The capacity of health service providers from VHTs to health centers was enhanced and built for disease surveillance and management. Ambulances were bought by members of Parliament (MP) and the government. This supported and eased the management of COVID-19 patients. In addition, the COVID19 pandemic attracted more funds to districts through government supplementary budget allocations and donor support," said GX\#33 (a 52-year-old male, DTF).

\section{On question 5, what were the main COVID-19 success stories from your hospital/district that you wish to share in your analysis?}

Themes developed on this subject were: (i) Successful implementation of the home-based care for COVID-19 patients (ii) increased productivity of industries that produce IPC materials (iii) Improved security of persons and property during the COVID-19 pandemic (iv) Increased community engagement, sensitization, and mobilization on COVID-19 and other health indicators (v) Improved performance of the health sector.

Several success stories were reported during the COVID-19 in this community of Northern Uganda, for example, the successful implementation of the home-based-care model, which helped reduce the burden of COVID-19 patients in healthcare facilities.

"Home-based care for COVID-19 patients has improved the standard care of patients and clients. Many community members have been able to buy some of the medicines required by themselves and have improved," said GX\#18 (a 45-year-old female health worker).

"A staff from our hospital who tested positive, was treated, became negative and recovered successfully, and has returned to work," said GX\#23 (a 44-year-old female health worker).

"........the success story is that the home-based management of COVID-19 has reduced patients' burden on health facilities," said GX\#1(a 43-year-old female health worker).

There was increased productivity in industries, especially those that produce facemasks, hand sanitizers, and protective wear.

"Success stories are that during the COVID-19 there has been increased productivity, revenue, and employment especially around factories that produce IPCs, PPEs, sanitizers, and facemasks," said GX\#1(a 43-year-old female health worker). 
The night curfew imposed on the population improved the general security of persons and property of the community in northern Uganda.

"The general security in our community has improved because of adherence to the night curfew regulations............" said GX\#2 (a 55-year-old male, member of security forces).

There are a reduced incidence and prevalence of road traffic accidents WASH-related infections such as diarrhea and cholera.

"The COVID-19 pandemic led to better maintenance of roads for easy movement of ambulances in communities. There were reduced cases of road traffic accidents in the period due to restrictions on the movement of vehicles and motorcycles," said GX\#33 (a 52-year-old male, DTF).

"There has been improvement in family hygiene, and this has caused a reduction in cases of diseases caused by poor hygiene such as diarrhea," said GX\#35 (a 38-year-old male, Politician).

Participants have mentioned that restrictions on public gatherings have reduced the incidence and prevalence of COVID-19 and other diseases that spread through physical contact from person to person in the community in northern Uganda.

"...... Restrictions on congregate settings, for example, churches, markets, bars, and lodges have reduced the spread of COVID-19 infection by reducing persons to persons' contacts," said GX\#2 (a 55-year-old male, member of security forces).

In addition, participants also observed that many people adopted more care of themselves through wearing facemasks in public and followed SOPS guidelines instituted by the government of Uganda. adherence of SOPS can keep one safe from contracting the virus," said GX\#12 (a 49-year-old male health worker).

"................. Improved responses to the coronavirus and community's attitudes have changed positively. People got tired of seeing people die in large numbers. A change in the attitude of people came, and there was increased facemask wearing in public by community members," said GX\#4 (a 40-year-old female, member of security forces).

Lastly, there was improved coordination of district-level responses and attitudinal change of the population to the COVID-19 pandemic and its management.

"...... a significant improvement in the epidemiological surveillance of diseases in our district has occurred with the COVID-19 pandemic," said GX\#21 (a 28-year-old male health worker).

"There has been increased commitment of health workers, especially those in CTUs. Government improved drug delivery and supplies, improved screening of patients at many points, increased fuel 
allocation for ambulances and hospitals, and this has eased work in hospitals and health facilities," said GX\#6 (a 45-year-old male health worker).

"A dedicated team at the CTUs that could not sleep were handy for the period of the pandemic. Intensive training of staff by WHO and UNICEF was beneficial. Health facility management support became essential and increased cooperation among staff at all levels," said GX\#1 (a 43-year-old female health worker).

"Community engagement on the COVID-19 prevention and control resulted in a decrease in the number of cases in the high-risk area of Puranga Ongonyo. Political and technical teams addressed this community's problem, decreasing new cases and massive testing uptake. Positive cases were followed and managed through the home-based care approach. Only a few cases were referred from the same community for hospital care and management. In addition, the transmission rate of the virus was reduced through risk communication by teams engaging, sensitizing, mobilizing, and supporting the community. Taskforce reactivation and formation was done from the district up to village level, and continuous surveillance ensured early detection and management of COVID-19 positive cases," said GX\#32 (a 47-year-old male health worker).

"Many people were willing to donate funds towards facilitation of activities of the district task force so that the cycle of COVID-19 transmission was broken; an 80-year-old woman demonstrated this by donating her UGX10,000/= shillings [equivalent to 2.5\$USD] to support her district task force (DTF). The community supported the treatment center by donating food items, amongst many other things. People were so committed to the task force's activities, and many members of the DTF would travel long distances to attend meetings to share their experiences and recommend what else to be done. This selfmotivation and commitment to the DTF were awesome. Radios and other media houses got involved in the dissemination of information to the local community, and this demonstrated collective effort to fight and eradicate COVID-19 in their communities," said GX\#33 (a 52-year-old male, DTF)

\section{On question 6, what were the main challenges faced by your staff and hospital/district during this COVID- 19 pandemic?}

Themes on the challenges were: (i) Lack of IPC materials for health workers, (ii) difficulty in accessing families by the community and task force members (iii) lack of cooperation of the community to guidelines (iv) widespread stigmatization among community members

Many participants mentioned several challenges health workers, security forces, district task forces, and communities faced during the COVID-19 pandemic.

\section{Lack of IPC and PPEs for health workers.}

"Health workers were not fully involved at the beginning of the pandemic, and there were problems of proper planning for the response. Lack of PPEs was one of the major problems, and health workers were not being protected," said GX\#9 (a 45-year-old male health worker). 
"There was an inadequate supply of personal protection equipment (PPE) while the Ministry of Health $(\mathrm{MOH})$ was recommending double masking whereas getting a single mask was already an issue and therefore individual health workers had to purchase their PPEs," said GX\#8 (a 33-year-old, female, health worker).

“...allowances for the frontline workers were not delivered. The general fatigue among health workers, an inadequate workforce, and funding gaps were problematic during the response to the pandemic," said GX\#12 (a 49-year-old male health worker).

"Some health workers contracted the virus, became very sick, while others died. There was an increased workload for health workers due to staff shortage, resulting in the cancellation of leaves for some staff. The discriminatory payment of allowances was witnessed as only staff in CTUs were paid, and therefore managing staff in other departments became difficult. PPEs were very few and inadequate; some were of poor quality," said GX\#16 (a 48-year-old female health worker).

"There was overwhelming patients' load due to an overwhelming number of COVID-19 cases and shortage of staff to care. In addition, health workers had movement disturbances at night due to the night curfews imposed by the government, where on some occasions, even health workers going to and from work were arrested and detained. Furthermore, supplies urgently required for treatment such as warfarin and vitamin $C$ were unavailable in many health facilities. These were the many challenges faced by the health workers during the pandemic," said GX\#27 (a 36-year-old female health worker).

"We had many problems with other medical emergencies, for example, maternal emergencies which were often referred to hospitals very late and many other medical and surgical emergencies that arrived late with many adverse events due to the movement restrictions imposed by the government," said GX\#29 (a

\section{6-year-old female health worker)}

"Lack of adequate facilitation, lack of PPEs, infection with COVID-19, inadequate staffing, overworking, burnout effects, and limited resources were problems experienced by health workers during the pandemic," said GX\#20 (a 41-year-old male health worker)

"Loss of dear ones and relatives, the fear of isolation, stigmatization, and high costs related to the treatment of COVID-19 grossly affected many health workers in this region. Many people lost their jobs, especially with the lockdown, and could not afford many basic requirements, leading to poor feeding due to lack of money to buy food. In addition, our school was closed, and many of our students became pregnant during the long layoff. This was combined with the lack of IPCs and other materials for the management of COVID-19, which negatively affected our work," said GX\#25 (a 63-year-old male health worker).

District task force members had problems accessing their families during the COVID-19 pandemic and the lockdowns. 
"During the lockdown, we had problems accessing our families, friends, workplaces, and the current economic recession has adverse consequences in our lives, and it is giving us a lot of anxiety and stress," said GX\#3 (a 54-year-old female, Politician).

"...there were problems with family interaction due to long-duration without physical contacts for some security officers. Many security officers did not go on annual leave. In contrast, others had their annual leaves canceled to ensure that there were enough officers available to handle the situation," said GX\#5 (a 59-year-old male, security forces).

\section{Members of security forces faced violent reactions from the public, and others became infected with the COVID-19.}

"Some communities became violent to the police during the lockdown when poverty was biting hard. There were violations of standard guidelines as a defiant response to government directives, and some community members physically attacked members of the security forces," said GX\#5 (a 59-year-old male, security forces).

"Some officers got infected with the COVID-19, many were sick for long and while others passed on during the period. The workload became greater because we lacked the workforce to handle all the assignments. In addition, people have been working under tension because of the fear of the virus. Family contacts have reduced because of curfew implementation and restrictions to the security forces," said GX\#13 (a 31-year-old, female, security forces)

Stigma among community members during the COVID-19 lockdowns and reduced engagement and sensitization of community due to the fear of the disease. Participants expressed widespread incidences of stigma in the community during the pandemic.

"Stigma on COVID-19 patients was widespread in the population. Communities thought that all health workers had the virus already, which created fear and anxiety in communities where health workers live. Health workers also became fearful that they may contract the virus considering the level of exposure they go through. There were inadequate IPC materials for health workers in the general ward and outpatient departments. There was overwhelming pressure on health workers to perform, and yet the work overload was too much, and equipment was in short supply" said, GX\#11 (a 41-year-old male health worker).

"....... challenges faced during the pandemic included reduced access to public transport. Limited community engagements and sensitization to achieve the desired health indicator, especially on routine immunization, in addition, there were too many bureaucracies at the task force offices," said GX\#1 (a 43year-old female health worker).

On question 7, what advice would you give to the region's population on how to protect themselves against the Coronavirus infection? 
Themes that evolved were: (i) Follow the IPC SOPS guidelines (ii) COVID-19 vaccination (iii) More research on drugs for treatment (iv) Adopting good feeding practices

In theme (i), many participants suggested several ways in which communities could respond during the COVID-19 pandemic to limit the spread and protect themselves against the virus.

"Stay at home, practice social distancing, use the SOPS, avoid large gatherings such as churches, markets, funerals, and games. Children and teachers should first be vaccinated before schools can reopen, and children should be taught in nearby schools," said GX\#2 (a 55-year-old male, member of security forces).

"All members of the community should undertake enrollment for mass vaccination, and this should be combined with social distancing and a general change in the mindset to fight the disease," said GX\#3 (a 54-year-old female, Politician).

"Accept it as a new situation and move away from traditional practices of conducting huge funerals, rituals, marriage ceremonies and embrace COVID-19 SOPS, and infection prevention and control (IPC)," said GX\#10 (54-year-old female, Politician).

"Adopting good practices, document herbal medicines and encourage good practices on the COVID-19 pandemic. All community members should practice resource accumulation and hard work to make resources available for the family. This should be followed by encouraging the culture of saving and strengthening facilities at home, schools, and hospitals to avoid importing COVID-19 infections," said GX\#14 (a 44-year-old male, DTF)

"We should encourage vaccination, observe the SOPS, regular hand washing and use hand sanitizers, regular exercises, and eating well as a means of surviving the pandemic," said GX\#1(a 43-year-old female health worker).

"We need to increase the uptake of COVID-19 vaccines, increase the use of IPC SOPS, for example, regular handwashing with soap and water, social distancing, emphasis on the home-based care model of management and adherence to the ministry of health guidelines," said GX\#20 (a 41-year-old, male, health worker).

"Listening to the health authorities and ensuring adequate observance of SOPS, utilizing the lockdown period to have quality family time to care for and parent children. In addition, we should increase food production through farming. Furthermore, we should develop a comprehensive plan to address the issue of long-term consequences of the lockdown, which remains a critical intervention for the future," said GX\#24 (a 39-year-old male health worker).

"Adhere to standard operating procedures (SOPS), taking advantage of the vaccination exercise currently being rolled out, and if eligible, one should become vaccinated. The vaccines are free of charge. Health systems should invest in various methods of reaching out to the public and communities, involve 
religious and cultural leaders to mobilize the communities," said GX\#29 (a 56-year-old female health worker).

"Eat a well-balanced diet to enhance immunity that can fight against the virus, observe the COVID-19 SOPS, go and seek medical attention when the signs and symptoms appear," said GX\#30 (a 35-year-old female health worker).

\section{Discussions}

This study on members of the COVID-19 district task forces in Northern Uganda has exposed a wide range of extraordinary conditions associated with the COVID-19 pandemic. It adds insights into opportunities and vast fields of the challenges they face. In response to the pandemic, health workers and health facilities had to rapidly adapt to new modes of service delivery in an economically challenged community. Participants reported multiple issues related to health workers, health facilities, health systems, the community, and the national government's response to the pandemic and how, in the process, the population of Northern Uganda browbeat numerous opportunities.

\section{On the challenges during the COVID-19 pandemic}

Participants in this study had to deal with a wide range of ethical quandaries on how to treat patients with COVID-19 without the required personal protection equipment (PPEs). This may have meant indulging in providing substandard care to the population and at the same time feeling the sense that their services were undervalued by their employers. There were nerve-wracking reports consistent with a view of moral injury as a perceived violation of one's professional integrity and obligations and concurrent feelings of being constrained from taking the ethically appropriate action [29].

Feelings of guilt and uncertainties on how COVID-19 patients and health workers were progressing during this time contributed to prolonged stress and other symptoms of burnout among health workers and the community. These had implications on whether health workers and the community would comply with the set guidelines for the management of COVID-19 [28]. As seen from responses of members of district task forces and health workers, there were observed open defiance to the SOPS and presidential directives in some communities in Northern Uganda. This partly explains in their view the reason for the heave in COVID-19 cases in Northern Uganda

Some members of the district task force recommended that executions of activities and duties should be done openly and satisfactorily to the task force committee and community, ensuring that every penny or kind contribution was well documented and accounted for. This was suggested to be followed quickly by processing funds to facilitate activities of task forces, review the standard policy on admissions of COVID-19 cases, and increase bed capacities of regional and general hospitals in Northern Uganda. They recommended the involvement of all medical staff in the preliminary planning and implementation processes of COVID-19 management and strategies for containment in the community. 
Some health workers reported that staff should be paid what they deserve, without prejudice. The allocated fund should be used for the purpose it was budgeted for and should be well accounted for. In addition, the government should prioritize more drug supplies and increase medical supplies and PPEs to health workers. This was expected to motivate health workers and support their quality-of-service delivery to the community they serve. The inadequate numbers and quality of PPEs for health workers during the surge may have in many ways contributed to many health workers contracting COVID-19 during the second wave. This had implications on the morale, resilience, motivation, and effectiveness of health workers during the second wave of COVID-19 in Northern Uganda.

Also, community members who tested positive for COVID-19 got worried and psychological anguish about their condition. Isolation from their families and communities after diagnosis made them feel abandoned by their people. This was compounded by the high level of community stigma on COVID-19 cases. These authors suggest that the Ugandan Government could appropriately handle this issue by adopting the grassroots approach to community mental health programs where counseling and psychosocial support to survivors of COVID-19 are conducted at the village level using properly trained VHTs.

Furthermore, most community members were underprivileged and didn't have funds to buy home therapies such as Zinc, azithromycin, Vitamin C, ginger, hand sanitizers, and facemasks, commonly used to manage the disease. The community found it very difficult and expensive to care for cases of COVID19 from home as families did not have enough rooms and money to isolate victims, buy PPEs and other items.

In addition, there was excessive fear of contracting the disease from patients they cared for. This situation was made worse by men who tested positive for COVID-19 turning violent and refusing to be isolated from their families. This situation deepened and was witnessed by increased incidences of domestic violence in some communities combined with the fear of contracting COVID-19 by some family members. These authors suggest that the Ugandan Ministry of Health could support communities in the home-based care management by providing drugs and protective wears to caregivers so that there is reduced risks of spread of COVID-19 infection to families and caregivers or at most provide food and drug vouchers for the affected families to ensure compliance to the home-based care management model.

\section{On the opportunities during the COVID-19 pandemic}

Despite the challenges mentioned above, several opportunities were presented to the region as the community experienced the COVID-19 pandemic. There was successful management of most COVID-19 patients using the home-based care model, where the majority of patients were successfully managed at home without referring to hospitals for further treatment. This home-based care management approach was adopted following guidance from the Ugandan Ministry of Health and World Health Organization (WHO), which recommended safe home care for patients with suspected COVID-19 infection who presented with mild symptoms and public health measures for managing their contacts [30]. 
Engagement, sensitization, and community mobilization for action against the virus were significant achievements during the pandemic. This was in line with the excellent principle of epidemic management, where the willingness and cooperation of the community to accept harsh measures became pillars for successful management of the epidemic [31]. This was also in line with WHO's recommendation where engagement, sensitization, mobilization, and involvement of communities in the management and control of the COVID-19 pandemic were considered critical [32]. This is contained in a WHO guideline intended to support teams working directly with communities during the COVID-19 pandemic. The guideline provides general guidance on community engagement during any disease outbreak response, including keeping an integrated response and outbreak prevention and response team [32].

One community in Northern Uganda observed that engagement of high-risk communities where cases of COVID-19 were increasing daily registered a sudden drop in the number of positive cases when health workers and members of the district task force engaged them for action against the spread of the virus. We authors argue that involvement and engagement of communities in prevention and control of any epidemic remain critical for sustainable and long-term prevention and management of the disease in question, and this was experienced in Northern Uganda [32].

During the lockdown period, many community members moved from towns to villages. They got involved in farming, resulting in increased household food production, more quality time with families, and higher income through sales of agricultural products. The pandemic provided a rare opportunity for the urban residents to find comfort in villages, have more quality family time, and get involved in useful activities, for example, farming, when most economic activities in towns were restricted due to the lockdown measures [32,33].

In addition, there has been increased availability of medical equipment, infrastructural improvements, availability of more funds, training of health workers, improved general security in the region, and successful recovery of many patients in this resource-limited environment of Northern Uganda. These opportunities were enormous during the COVID-19 pandemic and deserved mention for a community that is very much poorly resourced in many ways.

The Secretary-General of the World Health Organization (WHO) also mentioned in his address that, "no one would be safe from the COVID-19 pandemic until everybody was safe" [34]. This was a powerful message from the WHO boss and should be followed through so that all nations, communities, and peoples are safe from the COVID-19 now and in the future.

Also, efforts made by the Ugandan Government to overcome challenges shaped by the COVID19 pandemic were commendable, and these opportunities allowed Northern Uganda to enjoy rare opportunities in the health sector. It is hoped that opportunities presented by the pandemic could provide an atmosphere for health systems reforms, quality service delivery, improved surveillance of diseases with epidemic potential, and multistakeholder involvement in the management of epidemics in the future. 


\section{Strengths and limitations of this study}

These findings must be contextualized within the methodological strengths and limitations. We employed a qualitative study design using interview guides that prompted participants to describe their opinion on

the challenges and opportunities during the COVID-19 pandemic in remote areas of Northern Uganda. We recruited 36 participants with a wide age range (28-63 years) that resided in the four districts of the Acholi subregion in Northern Uganda. We provided participants with feedback and conducted external qualitative research experts to review our results. In addition, themes on participants' responses were not generated according to age, sex, or districts but on consistently essential issues on the COVID-19 over the period. This perhaps provides the strength and validity of our findings. Furthermore, our current study may form a basis for future studies on various groups as the COVID-19 pandemic progresses, especially in a resource-limited environment.

The snowballing sampling technique for recruiting participants may have limited several health workers or teams of district task forces from participating in this study. However, this was necessary as we conducted the investigation immediately after easing the second lockdown measures on COVID-19 in Uganda. Most restrictions were still in place, with everyone taking care not to have close physical contacts with any new person in their environment.

Furthermore, the strength of our study is based on real-time documentation of a wide range of health issues; this was after the second wave of the COVID-19 pandemic in Northern Uganda, where several community members lost their lives, others were infected, got treated, and luckily recovered.

This study had several limitations. We did not conduct any formal measurements or assessments of the mental health status of health workers when they reported stress, anxiety, burnout, and restlessness. Still, we relied on their qualitative narratives to present in this paper. Whether the information provided were accurate or not, the scope and limitations of our study could not verify all information using standard measuring tools for the mental health situations reported. Nevertheless, we believe that stress and psychological challenges of providing healthcare during the COVID-19 pandemic were likely similar across many sectors in the region and beyond our healthcare systems. Still, we acknowledge that further work in this low resource setting will be required in the future.

In addition, this study was conducted immediately after easing the second lockdown measures on the COVID-19 pandemic in Uganda. This finding may not fully describe the chronology of experiences during the first, lockdown, and second waves. It may be that the effect of the second wave we have described could be different from the first wave, which was not fully documented in this study.

\section{Conclusions}

Although the COVID-19 pandemic presented numerous challenges to low-to-middle-income countries and communities, some opportunities are worth mentioning. Information obtained on experiences have 
practical applications on opportunities, and this could be used to help communities organize and strategize on disease prevention and control during and beyond the COVID-19 pandemic.

\section{Abbreviations}

CTUs

COVID-19 treatment units

DTF

District task force

ICU

Intensive care unit

IPC

Infection, prevention, and control

SOPS

Standard operating procedures

VHTs

Village Health Teams

WASH

Water, sanitation, and hygiene

\section{Declarations}

Ethics approval and consent to participate: Ethical approval for the study was obtained from Gulu Regional Referral Hospital Ethics and Review Committee. All research methods were carried out according to relevant guidelines and regulations. Informed consent was obtained from all participants.

Consent for publication: All participants agreed to have this information published.

Availability of data and materials: Requests for anonymized data can be made to the corresponding author.

Competing interests: All authors declare no conflict of interest.

Funding: This project was funded mainly by DLK, ENI, and individual authors.

Authors' contributions: DLK was the lead researcher and managed the project. CO, SB, NAO, FWDO, JE, PA, PL, FPP, DA, JA, ENI, and JNO contributed to the study design, analysis, and writing-up. PL, JNO, SB, FWDO, and DLK conducted the interviews. DLK, ENI, SB, FWDO, JA, PL, and JNO contributed in analysis and manuscript writing-up. All authors read and approved the final manuscript.

Acknowledgments: We are very grateful to the health workers, members of the district force who generously participated in this study, and those who helped us develop this study. We thank all members 
who participated in the interviews, transcription, and final write-up of this report.

\section{Authors' information:}

${ }^{* 1}$ Dr. Eric Nzirakaindi Ikoona (EZI) is an adjunct Professor at ICAP in the University of Columbia, Freetown, Sierra Leone; ${ }^{2}$ Johnson Nyeko Oloya (JNO) is a medical officer and member of the Uganda Medical Association, UMA-Acholi branch, Gulu City, Uganda; ${ }^{2,3}$ Dr. Christopher Okot (CO) is a Medical Officer Special Grade, Department of surgery at Gulu Regional Referral Hospital, Gulu City, Uganda; ${ }^{2,3} \mathrm{Dr}$. Stephen Baguma (SB) is a Medical Officer in the Department of Obstetrics and Gynecology at Gulu Regional Referral Hospital, Gulu City, Uganda; ${ }^{2,3}$ Dr. Paska Apiyo (PA) is a Consultant Physician at Gulu Regional Referral Hospital, Gulu City, Uganda; ${ }^{4}$ Dr. Nelson Onira Alema (NOA) is a Lecturer in Anatomy at Gulu University, Faculty of Medicine, Department of Anatomy, Gulu City, Uganda; ${ }^{2}$ Dr. Freddy WD Oyat (FWDO) is a senior physician, a public health specialist, and member of Uganda Medical Association, UMA-Acholi branch, Gulu City, Uganda; ${ }^{2,5}$ Dr. Paska Layet (PL) was a Senior Clinician and Public Health Specialist at St. Mary's Hospital Lacor, Gulu City, Uganda; ${ }^{2,6}$ Dr. Francis Pebalo Pebolo (FPP) is a Lecturer at Gulu University, Faculty of Medicine, Department of Reproductive Health, Gulu City, Uganda; ${ }^{2,7}$ Dr. Denis Acullu (DA) is a Senior Consultant Radiologist at the Aga Khan Hospital, Mombasa, Kenya. ${ }^{2,8}$ Dr. Judith Aloyo is a Technical Director at the Rhites-N, Acholi, Gulu City, Uganda.

${ }^{2,9}$ Prof. David Lagoro Kitara (DLK) is a Takemi fellow of Harvard University and a Professor at Gulu University, Faculty of Medicine, Department of Surgery, Gulu City, Uganda.

\section{References}

1. Wu Zunyou, McGoogan M Jennifer. Characteristics of and important lessons from the coronavirus disease 2019 (COVID-19) outbreak in China: summary of a report of 72314 cases from the Chinese Center for Disease Control and Prevention. JAMA.2020;323(13):1239-1242

2. Infographic. Coronavirus Spreads through Africa. African Centers for Strategic Studies. 2021 https://africacenter.org/spotlight/coronavirus-spreads-through-africa/ (accessed on 1 August 2021).

3. Yuen KS, Ye ZW, Fung SY, Chan CP, Jin DY. SARS-CoV-2 and COVID-19: The most critical research questions. Cell Biosci. 2020;10:40

4. Zheng J. SARS-CoV-2: An Emerging Coronavirus that Causes a Global Threat. Int J Biol Sci. 2020; 16:1678-1685

5. Fauci AS, Lane HC, Redfield RR. Covid-19-Navigating the Uncharted. N Engl J Med. 2020; 382:12681269

6. Zhang T, He Y, Xu W, Ma A, Yang Y, Xu KF. Clinical trials for the treatment of Coronavirus disease 2019 (COVID-19): A rapid response to urgent need. Sci. China Life Sci. 2020;63:774-776

7. WHO. Infection Prevention and Control during Health Care When Novel Coronavirus (CoV) Infection is Suspected. 2021 Available online: https://www.who.int/publications/i/item/10665-331495 
(accessed on 13 August 13, 2021).

8. Voysey M, Clemens SAC, Madhi SA, Weckx LY, Folegatti PM, Aley PK et al. Safety and efficacy of the ChAd0x1 nCoV-19 vaccine (AZD1222) against SARS-CoV-2: An interim analysis of four randomized controlled trials in Brazil, South Africa, and the UK. Lancet. 2020;397:99-111

9. Polack FP, Thomas SJ, Kitchin N, Absalon J, Gurtman A, Lockhart S et al. Safety and Efficacy of the BNT162b2 mRNA Covid-19 Vaccine. N Engl J Med. 2020;384:1576-1577

10. Baden LR, El Sahly HM, Essink B, Kotloff K, Frey S, Novak R, Diemert D et al. Efficacy and Safety of the mRNA-1273 SARS-CoV-2 Vaccine. N Engl J Med. 2020;384:403-416

11. FDA. Vaccines and Related Biological Products Advisory Committee Meeting. 2021. Available online: https://www.fda.gov/media/146217/download (accessed on 13 August 2021).

12. Novavax COVID-19 Vaccine Demonstrates 89.3\% Efficacy in UK Phase 3 Trial. 2021. Available online:https://ir.novavax.com/newsreleases/news-release-details/novavax-covid-19-vaccinedemonstrates-893-efficacy-uk-phase-3 (accessed on 1 August 2021).

13. Logunov DY, Dolzhikova IV, Shcheblyakov DV, Tukhvatulin Al, Zubkova OV, Dzharullaeva AS, et al. Safety and efficacy of a rAd26 and rAd5 vector-based heterologous prime-boost COVID-19 vaccine: An interim analysis of a randomized controlled phase 3 trial in Russia. Lancet. 2021; 397:671-681

14. Sinopharm's COVID-19 Vaccine 79\% Effective, Seeks Approval in China. 2021. Available online: https://www.reuters.com/article/ushealth-coronavirus-china-vaccine/sinopharms-covid-19-vaccine79-effective-seeks-approval-in-china-idUSKBN2940C8 (accessed on 1 August 13, 2021).

15. COVID-19 Vaccines. Available online: https://www.who.int/emergencies/diseases/novel-coronavirus2019/covid-19-vaccines (accessed on 13 August 2021).

16. First COVID-19 COVAX Vaccine Doses Administered in Africa. Available online: https://www.unicef.org/press-releases/firstcovid-19-covax-vaccine-doses-administered-africa. (Accessed on 13 August 2021).

17. Nkengasong JN, Ndembi N, Tshangela A, Raji T. COVID-19 vaccines: How to ensure Africa has access. Nature. 2020; 586:197-199

18. WHO. Ensuring equitable access to COVID-19 vaccines. Bull World Health Organ.2020;98:826-827

19. David Lagoro Kitara and Eric Nzirakaindi Ikoona. COVID-19 pandemic, Uganda's Story. Pan Afr Med J. 2020;35(2):51

20. CGTN. The second wave of COVID-19 dampens Uganda's economic recovery. 2021. Newsaf.can.com/news/2021-8-14/second wave-of-covid-19-dampens-Uganda's-economic-recovery/

21. La Croix international staff/Uganda. Uganda was hit hard by a second COVID-19 wave. 2021. Internal.lacroix.com/news/world/Uganda-hit-hard-by-second-wave-covid-19 wave/14679.

22. Palinkas LA, Horwitz SM, Green CA, Wisdom JP, Duan N, Hoagwood K. Purposeful sampling for qualitative data collection and analysis in mixed method implementation research. Admin Pol Ment Health. 2015;42(5):533-44 
23. Mark Donald C Reñosa, Chanda Mwamba, Ankita Meghani, Nora S West, Shreya Hariyani, William Ddaaki, Anjali Sharma, et al,. Selfie consents, remote rapport, and Zoom debriefings: collecting qualitative data amid a pandemic in four resource-constrained settings. BMJ Global Health. 2020;6:e004193. doi:10.1136/ bmjgh-2020-004193

24. Ritchie MDC, Jane Lewis, Carol McNaughton Nicholls, and Rachel Urmston. Designing and Selecting Samples. In Ritchie J, Lewis J, McNaughton Nicholls C, and Ormston R. (eds) Qualitative research practice: a guide for social science students and researchers. 2013. Sage: London.

25. O'Brien BC, Harris IB, Beckman TJ, Reed DA, Cook DA. Standards for reporting qualitative research: a synthesis of recommendations. Acad Med. 2014;89(9):1245-51

26. Braun V and Clarke V. Using thematic analysis in psychology. Qualitative Research in Psychology. 2006;3(2):77-101

27. Tufford $L$ and Newman P. Bracketing in qualitative research. Qualitative Social Work. 2012; 11(1):80-96

28. Booth A, Hannes K, Harden A, Noyes J, Harris J \& Tong A. COREquation (consolidated criteria for reporting qualitative studies). In D Moher, DG Altman, KF Schulz, I Simera \& E Wager (Eds.), Guidelines for writing health research: A user's manual,2014: 214-226. Oxford, UK: John Wiley.

29. Lamiani G, Borghi L, Argentero P. When healthcare professionals cannot do the right thing: a systematic review of moral distress and its correlates. J Health Psychol. 2015;22(1):51-67

30. WHO. Home care with patients with COVID-19 presenting with mild symptoms and management of their contacts. Interim Guidance (On 17th March 2020). OCHA services, Reliefweb.

31. Eric Nzirakaindi Ikoona and David Lagoro Kitara. A proposed framework to limit post-lockdown community transmission of COVID-19 in Africa. Pan Afr Med J. 2021;38:303

32. WHO. Community engagement during the COVID-19, a guide for a community facing staff. Reliefweb.int/sites/reliefweb.int. /files/resources/gd-covid-19-oxfam-community-engagement guide270420

33. David Lagoro Kitara, Eric Nzirakaindi Ikoona. Proposed strategies for easing COVID-19 lockdown measures in Africa. Pan Afr Med J. 2020; 36:179

34. WHO. The COVID-19 pandemic is an opportunity to re-imagine human mobility posted on June 3 , 2020.

\section{Supplementary Files}

This is a list of supplementary files associated with this preprint. Click to download.

- Additionalfile1.docx

- Additionalfile2.docx

- Additionalfile3.docx 